CASE REPORT

\title{
Bacillary Angiomatosis in an HIV-positive Patient Following a Goat Bite
}

\author{
Roshni Kakitha ${ }^{1}$, Sreedevi Ambujam², Ben Easow George ${ }^{3}$
}

\begin{abstract}
Keywords: Bacillary angiomatosis, Goat bite, HIV.

\section{INTRODUCTION}

Bacillary angiomatosis (BA) also called epitheloid angiomatosis is a bacterial infection peculiar to HIV and is rare in the immunocompetent. It is caused by Bartonella henselae (usually found in cats) or Bartonella quintana (usually found in body louse) species with cutaneous and parenchymal manifestations. ${ }^{1}$ It is characterized by vascular skin lesions resembling pyogenic granuloma (PG). ${ }^{2}$ It has been reported to be acquired from cats or by trauma. ${ }^{3}$
\end{abstract}

Bacillary angiomatosis (BA) is caused by Bartonella henselae or Bartonella quintana reported to be acquired from cats or by trauma. A 40-yearold widow presented with a single large painful tumor over the left index finger at the site of a goat bite. With the history of goat bite, rapid increase in size, a uniformly soft purplish lobulated tumor, which bled on touch, and histopathology demonstrating proliferation of capillary-sized vessels, in the background of HIV infection, the differential diagnosis was narrowed down to BA and giant pyogenic granuloma (PG). All clinical diagnoses cannot be evidence based all the time, especially in resource-poor settings. Therapeutic trials are well-known in dermatology and the positive result needs to be considered as evidence for diagnosis in those situations. The remarkable clinical response to oral doxycycline, we feel, could be considered diagnostic of Bartonella infection, and hence, we report this case.

Key messages: All clinical diagnoses cannot be evidence based all the time, especially in resource-poor settings. Therapeutic trials are well-known in dermatology. The positive result needs to be considered as evidence for diagnosis sometimes. The remarkable response to oral doxycycline of this goat bite incited skin lesion in our HIV-positive patient, we feel, could be considered diagnostic of Bartonella infection.

SBV Journal of Basic, Clinical and Applied Health Science (2020): 10.5005/jp-journals-10082-02238

\section{Case Description}

A 40-year-old widow presented with a single large painful tumor over the left index finger at the site of a goat bite sustained 7 months ago. Two weeks later, patient noticed a red papule which slowly enlarged to the current size.

Patient was emaciated, anemic, and local examination revealed a single, well-defined, purplish, lobulated, uniformly soft swelling circumferentially involving almost $70 \%$ of the left index finger. Some of the lobules had yellow adherent crusts on their surface and few bled on palpation. There was loss of nail plate with blood clots on the nail bed. Retained suture material was seen sticking out of the lesion. Certain interlobular spaces showed remnants of the leafy paste that the patient had applied earlier (Fig. 1).

Differential diagnoses of foreign body granuloma (FBG) (to the retained suture material), PG, BA, and squamous cell carcinoma were considered. Patient was admitted and investigated (blood and urine tests, ultrasonography, and radioimaging) to rule out systemic involvement. She was found to be positive for HIV but the CD4 count was not done, as patient could not afford the test. It is assumed that the CD4 count is less than 100 cells/microliter as this disease indicates that.
${ }^{1}$ Titoria's Clinics, Noida, Uttar Pradesh, India

${ }^{2}$ Department of Dermatology, Venereology and Leprosy, Believers Church Medical College, Thiruvalla, Kerala, India

${ }^{3}$ Department of Dermatology, Venereology and Leprosy, Oliva Clinic, Kochi, Kerala, India

Corresponding Author: Roshni Kakitha, Titoria's Clinics, Noida, Uttar Pradesh, India, Phone: +91 7708541823, e-mail: k.roshni55@gmail.com

How to cite this article: Kakitha R, Ambujam S, George BE. Bacillary Angiomatosis in an HIV-positive Patient Following a Goat Bite. J Basic Clin Appl Health Sci 2020;3(1):35-37.

Source of support: Nil

Conflict of interest: None

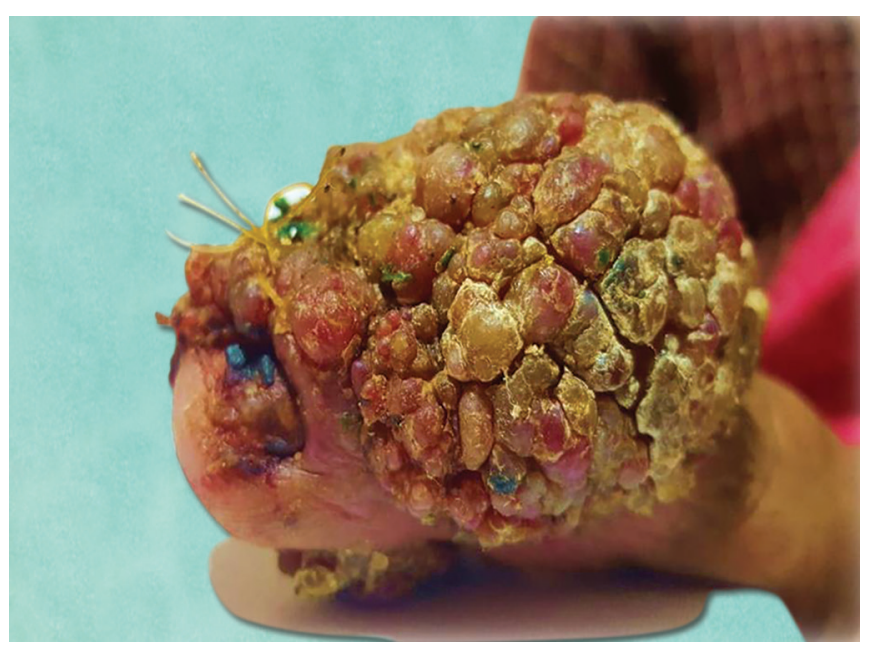

Fig. 1: Lesion at the time of presentation

() The Author(s). 2020 Open Access This article is distributed under the terms of the Creative Commons Attribution 4.0 International License (https://creativecommons. org/licenses/by-nc/4.0/), which permits unrestricted use, distribution, and non-commercial reproduction in any medium, provided you give appropriate credit to the original author(s) and the source, provide a link to the Creative Commons license, and indicate if changes were made. The Creative Commons Public Domain Dedication waiver (http://creativecommons.org/publicdomain/zero/1.0/) applies to the data made available in this article, unless otherwise stated. 


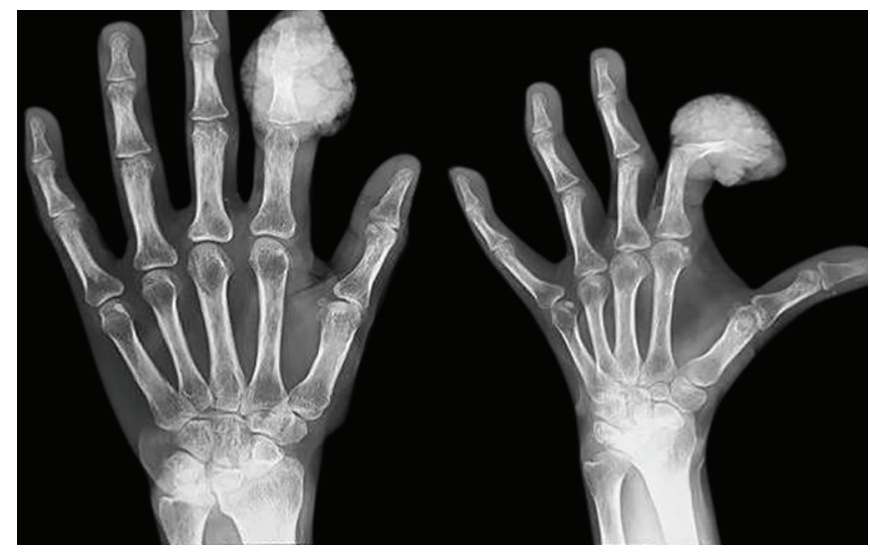

Fig. 2: X-ray of the involved hand at the time of presentation

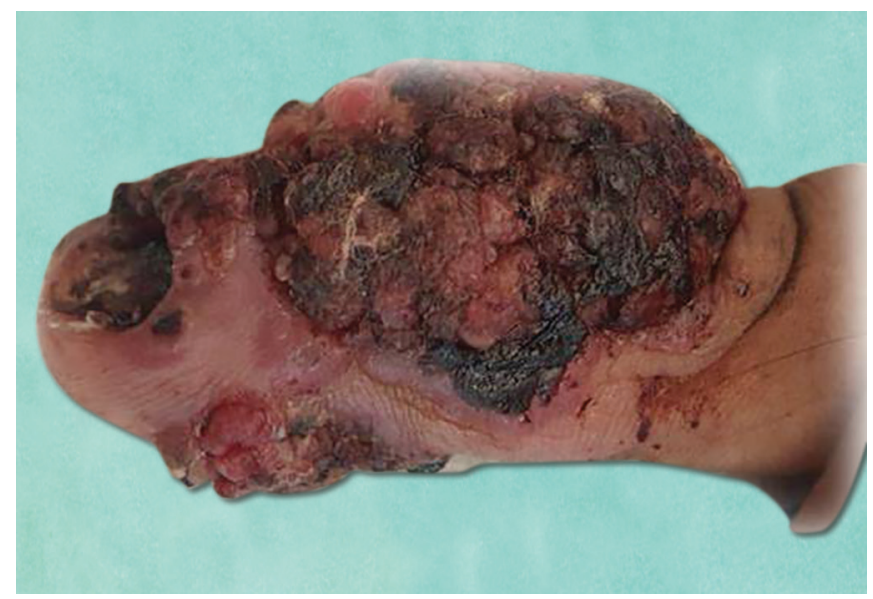

Fig. 4: Lesion after 2 weeks of treatment with doxycycline

$X$-ray of the left index finger revealed a dense soft tissue lesion not continuous with the underlying bone and without any evidence of lytic lesions (Fig. 2).

Overgrowth of Staphalococcus aureus was seen on chocolate agar inoculated with blood aspirated from the lesion, which was considered as a contaminated sample. Further samples were not taken as the patient was started on treatment.

Histopathological examination (HPE) showed proliferation of capillary-sized blood vessels along with chronic inflammatory cells and fibrosis in the deep dermis (Fig. 3). Warthin Starry stain, a silver nitrate-based stain used for the definitive diagnosis of BA was not done due to logistic difficulties and unaffordability by the patient.

With the history of goat bite, rapid increase in size, a uniformly soft purplish lobulated tumor, which bled on touch, HPE demonstrating proliferation of capillary-sized vessels, in the background of HIV infection, the differential diagnosis was narrowed down to $B A$ and giant $P G$.

Both $B A$ and $P G$ can be incited by trauma and are clinically indistinguishable. If left untreated, BA will prove fatal while PG will remain localized.

Hence, patient was started on Doxycycline 100 mg twice daily, the standard treatment for BA. ${ }^{3}$ She was advised to continue the treatment for 3 months. Two weeks later, upon reviewing the patient, it was seen that the tumor had shrunken and vascularity had decreased. The contour of the finger was visible (Fig. 4-2 weeks posttreatment). However, the patient was lost for further follow-up.

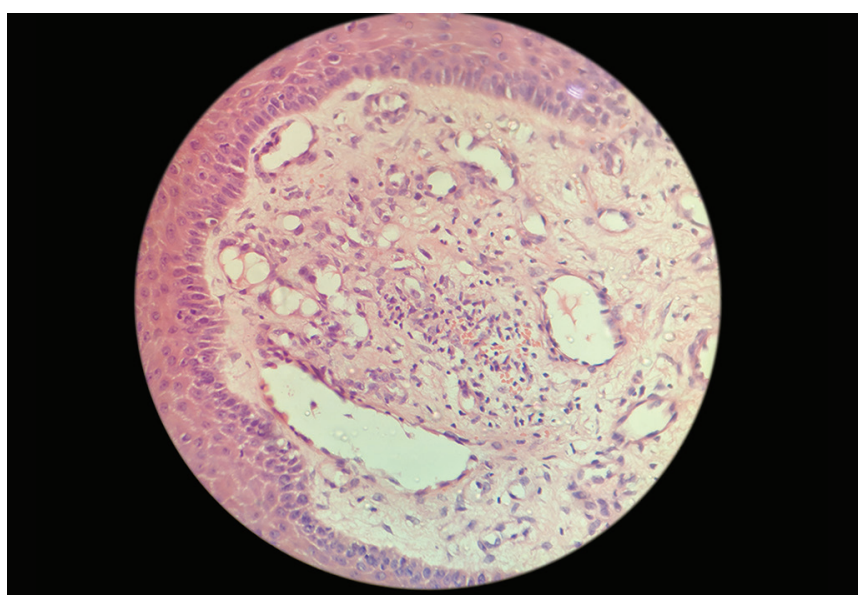

Fig. 3: Histopathological examination, $\mathrm{H}$ and $\mathrm{E}$ stain, 100x

\section{Discussion}

Bacillary angiomatosis is a bacterial infection caused by Bartonella henselae and Bartonella quintana and almost exclusively seen in HIV-infected patients with generally a CD4 count of less than $50 .{ }^{4}$ The infection is acquired from cats majority of times. A literature search did not reveal acquisition of this infection from goats or other animals ${ }^{1}$ apart from a single study where the organism was isolated from the ticks on a goat. ${ }^{5}$ Clinically, BA may resemble PG. ${ }^{3}$ The former responds to long-term (at least 8 weeks) oral doxycycline and erythromycin, while the latter needs to be excised or cauterized. ${ }^{3}$ Untreated BA can be fatal, with patients dying of visceral disease or respiratory compromise from obstructing lesions. ${ }^{2}$ Our patient had a PG-like lesion that appeared 2 weeks after a trauma induced by goat bite.

Bartonella is a very fastidious bacteria and its culture is difficult. It takes at least a month to notice growth, if at all any. ${ }^{2}$ In our patient, the aspirate culture on chocolate agar grew only Staphylococcus aureus.

Obtaining adequate tissue from the skin lesions of BA for HPE is also difficult due to the highly friable nature of the tissue. ${ }^{3}$ Both BA and PG have similar HPE findings as that of PG in low power. ${ }^{2}$

The HPE of tissue from the swelling in the patient revealed blood vessel proliferation. Absence of granulomas ruled out FBG to retained suture materials and absence of cellular atypia excluded malignancy.

Bacillary angiomatosis is confirmed by demonstration of bacilli from tissue by special stains like Warthin Starry stain. ${ }^{1}$

The limitation of this case report is that we were unable to do a diagnostic HPE with Warthin Starry stain or PCR for Bartonella due to logistic difficulties and other factors beyond our control. We could not make a diagnosis of BA confidently in this context due to lack of specific investigations described in the literature. A dramatic response to doxycycline in two weeks, we feel, ruled out $P G$, leaving $B A$ as the only probable diagnosis.

\section{Conclusion}

All clinical diagnoses cannot be evidence based all the time, especially in resource poor settings. The practice of evidencebased medicine means 'integrating individual clinical expertise with the best available external clinical evidence from systematic research'. Today's practice of strict adherence to evidence-based 
medicine could devalue the rich knowledge that accumulates with clinical experience. It promotes formulaic "cookbook medicine", discouraging deliberation and clinical reasoning and leading to automatic decision which is excessively algorithmic. ${ }^{6,7}$

Therapeutic trials are well-known in treating cutaneous tuberculosis, fungal infections, and scabies, and the positive result needs to be considered as evidence for diagnosis in those situations.

The remarkable clinical response to oral doxycycline (Figs 1 and 3) of this goat bite incited skin lesion in our HIV-positive patient, we feel, could be considered diagnostic of Bartonella infection, and hence, we report this case.

\section{References}

1. Bolognia JL. Dermatology: ExpertConsult. 3rd edn., Edinburgh: Elsevier; 2012.
2. James WD, Elston DM, Berger TG. Andrews' diseases of the skin: clinical dermatology. 12th edn., Philadelphia, PA: Elsevier; 2016. p. 965.

3. Griffiths C, Barker J, Bleiker T, Chalmers R, Creamer D. Rook's textbook of dermatology. 9th edn, Chichester, West Sussex, Hoboken, NJ: John Wiley and Sons Inc.; 2016.

4. Goldsmith LA, Katz SI, Gilchrest BA, Paller AS, Leffell DJ, Wolff K, et al. Fitzpatrick's Dermatology in General Medicine. 8th edn., New York: The McGraw-Hill Companies, Inc.; 2012.

5. Sykes JE, Lindsay LL, Maggi RG, Breitschwerdt EB. Human coinfection with Bartonella henselae and two hemotropic mycoplasma variants resembling mycoplasma ovis. J Clin Microbiol 2010;48(10):3782-3785. DOI: 10.1128/JCM.01029-10.

6. Sackett DL, Rosenberg WMC, Gray JA, Haynes RB, Richardson WS. Evidence based medicine: what it is and what it isn't. Br Med J 1996;312(7023):71-72. DOI: 10.1136/bmj.312.7023.71.

7. Greenhalgh T, Howick J, Maskrey N, Evidence Based Medicine Renaissance Group. Evidence based medicine: a movement in crisis? BMJ 2014;348:1-7. DOI: 10.1136/bmj.g3725. 